AS WE SEE IT

\title{
Fidelity and flexibility in coral symbioses
}

\author{
Andrew H. Baird ${ }^{1, *}$, Vivian R. Cumbo ${ }^{1}$, William Leggat ${ }^{1,2}$, \\ Mauricio Rodriguez-Lanetty ${ }^{1,3}$
}

${ }^{1}$ ARC Centre of Excellence for Coral Reef Studies, James Cook University, Townsville, Queensland 4811, Australia
${ }^{2}$ School of Molecular Science, James Cook University, Townsville, Queensland 4811, Australia
${ }^{3}$ ARC Centre of Excellence for Coral Reef Studies, University of Queensland, St Lucia, Queensland 4072, Australia

\begin{abstract}
Understanding whether or not corals have the flexibility to change their complement of symbionts to adapt to changing climate is an important goal in reef ecology studies. While host fidelity to a single clade of symbiont is the dominant pattern in present-day corals, current estimates of flexibility are unreliable, because few studies have measured it rigorously and with adequately sensitive genetic techniques. Furthermore, flexibility must be explored at the level of the subclade, because generalisations of physiological performance among clades of Symbiodinium are not valid. In addition, we should not necessarily expect to see shifts among symbionts without distinct and enduring changes in environmental conditions. The few biogeographical comparisons available suggest that when corals encounter a new environment they have the flexibility to acquire different symbionts. Flexibility in the acquisition of symbionts is common at the time of infection, which in most corals occurs at, or shortly after, settlement. Consequently, flexibility is likely to be a feature of the life history of all species that must reacquire symbionts in each new generation.
\end{abstract}

KEY WORDS: Coral reefs $\cdot$ Climate change $\cdot$ Evolution $\cdot$ Symbiodinium $\cdot$ Symbiosis

Coral reefs are under severe threat from many sources, including rising sea surface temperature caused by climate change (Hughes et al. 2003). A major concern is that the accelerating rate of environmental change could exceed the capacity of coral species to acclimate and/or adapt (Hoegh-Guldberg 1999). One mechanism that may allow zooxanthellate corals to respond in ecological time is for the host to switch to a more thermally tolerant symbiotic partner (Buddemeier \& Fautin 1993). A number of authors have recently presented convincing data which suggest that few coral symbioses host more than one type of symbiont (Knowlton \& Rohwer 2003, Goulet 2006; but see Baker \& Romanski 2007). This lack of flexibility in present-day coral-algae symbioses has led some to argue that changing symbionts to cope with climate change is, therefore, not an option for most coral species (e.g. Goulet 2006). However, we believe current estimates of flexibility in coral-algal symbioses are unreliable for reasons we outline below. To make further progress towards understanding the potential of host flexibility as a mechanism for acclimation, we need to recognise that host flexibility is a trait that varies among individuals. Furthermore, we need to be clear about the types of symbiont change that are meaningful, the environmental conditions that might induce symbiont change, and at which point in the life history of coral species symbiont change is most likely to occur.

What type of change among symbionts within the host is relevant when considering acclimation to stress? If we are interested in physiological differences among symbionts, then the sub-clade must be the focus, because generalisations of functional difference among clades are no longer tenable (Savage et al. 2002). For example, there are both heat tolerant and 
heat susceptible sub-clades within both Clades C (Bhagooli \& Hidaka 2004) and D Symbiodinium (Tchernov et al. 2004). Indeed, characterisation of Symbiodinium phenotypic differences has lagged far behind our ability to genotype sub-clades, partly because many Symbiodinium are difficult to maintain in culture, making it difficult to determine the ecological significance of genotypic differences. Consequently, estimates that $25 \%$ of species can host more than one clade (e.g. Goulet 2006) may underestimate flexibility, because the relevant question is: how many species can host more than one sub-clade?

Similarly, where should we be looking for flexibility in the host? We argue it is at the individual. While few studies have specifically set out to examine flexibility within species, the dominant pattern, particularly in the Indo-Pacific, is for all colonies of a species to host a single symbiont (Knowlton \& Rohwer 2003, LaJeunesse et al. 2003). While recent work with more sensitive techniques indicates that a much higher proportion of host populations contain multiple clades (Mioeg et al. 2007), it may not be correct to characterise a species as flexible on the basis of a trait shared by few individuals.

Furthermore, should we expect to see changes in present-day coral symbioses, even if flexibility is an intrinsic feature of most species? While sea surface temperatures are trending upward, the absolute change at any one location over the last $20 \mathrm{yr}$ is generally $<0.5^{\circ} \mathrm{C}$ (Hoegh-Guldberg 1999, IPCC 2007). Is such an increase sufficient to provide the ecological opportunity for heat tolerant strains to out-compete susceptible strains? Are there any good tests of flexibility available in present-day coral symbioses? We suggest the best place to look for flexibility is where there is a distinct and lasting difference in environmental conditions; e.g. colonies of the same species at different depths, or in different regions. Depth patterns of association are, however, inconclusive (Thornhill et al. 2006). In some species, such as Montastrea annularis, colonies host different symbionts at different depths (Rowan et al. 1997). In contrast, there is no correlation between symbionts and depth in 5 morphospecies of Madracis (Diekmann et al. 2002). However, in the few species sampled over a broad geographical range, symbionts vary predictably with latitude. For example, all colonies of Plesiastrea versipora host stable populations of Clade B on the temperate southeastern coast of Australia, whereas subtropical and tropical populations host stable populations of Clade C (Rodriguez-Lanetty et al. 2001). Similarly, colonies from the sea anemone Anthopleura elegantissima host only Symbiodinium muscatinei in high latitudes and only $S$. californium in lower latitudes (LaJeunesse \& Trench 2000). These biogeographical data suggest that when species need to respond to novel environments, they have the flexibility to do so.

If changes in coral symbioses are to be induced by rising sea surface temperature, how is this likely to happen? The current focus of research has been on adult colonies shuffling or switching among symbionts in response to acute disturbances, such as bleaching (Baker 2001, Baker et al. 2004). We suggest that change is more likely to occur between generations, i.e. when symbiosis is re-established. For coral species, most of which lack maternal transmission of symbionts, initial infection occurs in larvae or early juveniles, when they are much more flexible than adults. For example, juveniles of Acropora tenuis regularly harbour mixed assemblages of symbionts, whereas adults almost invariably host a single clade (Little et al. 2004). Similarly, larvae of Fungia scutaria ingest symbionts from multiple hosts, whereas adult colonies typically host a single clade (Weis et al. 2001), a process moderated by recognition events after infection (Rodriguez-Lanetty et al. 2006). Consequently, flexibility is potentially part of the life history of every coral with horizontal transmission of symbionts ( $>75 \%$ of hermatypic corals, but interestingly, only $\sim 50 \%$ of corals in the Caribbean), and each sexual reproductive event provides the opportunity for the symbiosis to change. There is no need for acute disturbance, such as bleaching, to induce this change. Certainly, under current environmental conditions, even species that are flexible at the time of infection have strong fidelity as adults (Little et al. 2004). However, as sea temperatures rise, juveniles hosting thermo-tolerant sub-clades may be favoured and new symbiotic combinations may emerge in adult populations. Whether these changes can occur quickly enough to prevent the future degradation of reef corals remains an open question.

Finally, we believe much of the current literature creates the impression that changing symbionts is the most likely mechanism by which corals may adjust to climate change. This view does not give ample consideration to the fact that both partners in the association have the capacity to evolve, and that there are many host and algal-based mechanisms for acclimation (Coles \& Brown 2003). Furthermore, it is increasingly apparent that evolution by natural selection can occur very rapidly in some situations (Carroll et al. 2007) and therefore there may be no need to postulate novel mechanisms of acclimation, such as changing symbionts. Nonetheless, flexibility of symbiont association as a trait in host populations should be addressed, but progress can best be assured by searching for flexibility in the most appropriate places. 
Acknowledgements. This study was partially supported by the 21st Century Center of Excellence (COE) program of the University of the Ryukyus. We thank the participants of the 2007 COE Summer Program at Sesoko Station for valuable discussion of this topic, and one anonymous reviewer for many comments that greatly improved the manuscript.

\section{LITERATURE CITED}

Baker AC (2001) Reef corals bleach to survive change. Nature 411:765-766

Baker AC, Romanski AM (2007) Multiple symbiotic partnerships are common in scleractinian corals, but not in octocorals: Comment on Goulet (2006). Mar Ecol Prog Ser 335:237-242

Baker AC, Starger CJ, McClanahan TR, Glynn PW (2004) Corals' adaptive response to climate change. Nature 430: 741

Bhagooli R, Hidaka M (2004) Photoinhibition, bleaching susceptibility and mortality in two scleractinian corals, Platygyra ryukyuensis and Stylophora pistillata, in response to thermal and light stresses. Comp Biochem Physiol A Mol Integr Physiol 137:547-555

Buddemeier RW, Fautin DG (1993) Coral bleaching as an adaptive mechanism: a testable hypothesis. Bioscience 43:320-326

Carroll SP, Hendry AP, Reznick DN, Fox CW (2007) Evolution on ecological time-scales. Funct Ecol 21:387-393

Coles SL, Brown BE (2003) Coral bleaching: capacity for acclimatization and adaptation. Adv Mar Biol 46: $183-223$

Diekmann OE, Bak RPM, Tonk L, Stam WT, Olsen JL (2002) No habitat correlation of zooxanthellae in the coral genus Madracis on a Curacao reef. Mar Ecol Prog Ser 227: 221-232

Goulet TL (2006) Most corals may not change their symbionts. Mar Ecol Prog Ser 321:1-7

Hoegh-Guldberg O (1999) Climate change, coral bleaching and the future of the world's coral reefs. Mar Freshw Res 50:839-866

Hughes TP, Baird AH, Bellwood DR, Card M and 13 others (2003) Climate change, human impacts, and the resilience of coral reefs. Science 301:929-933

IPCC (Intergovernmental Panel on Climate Change) (2007) Working Group 1 Report: the physical science basis. UNEP, Geneva

Editorial responsibility: Howard Browman (Associate Editorin-Chief), Storebø, Norway
Knowlton N, Rohwer F (2003) Multispecies microbial mutualisms on coral reefs: the host as a habitat. Am Nat 162:S51-S62

LaJeunesse TC, Trench RK (2000) Biogeography of two species of Symbiodinium (Freudenthal) inhabiting the intertidal sea anemone Anthopleura elegantissima (Brandt). Biol Bull (Woods Hole) 199:126-134

LaJeunesse TC, Loh WKW, van Woesik R, Hoegh-Guldberg O, Schmidt GW, Fitt WK (2003) Low symbiont diversity in southern Great Barrier Reef corals, relative to those of the Caribbean. Limnol Oceanogr 48:2046-2054

Little AF, van Oppen MJH, Willis BL (2004) Flexibility in algal endosymbioses shapes growth in reef corals. Science 304:1492-1494

Mioeg JC, van Oppen MJH, Cantin NE, Stam WT, Olsen JL (2007) Real-time PCR reveals a high incidence of Symbiodinium clade D at low levels in four scleractinian corals across the Great Barrier Reef: implications for symbiont shufffling. Coral Reefs 26:449-457

Rodriguez-Lanetty M, Loh W, Carter D, Hoegh-Guldberg O (2001) Latitudinal variability in symbiont specificity within the widespread scleractinian coral Plesiastrea versipora. Mar Biol 138:1175-1181

Rodriguez-Lanetty M, Wood-Charlson EM, Hollingsworth LL, Krupp DA, Weis VM (2006) Temporal and spatial infection dynamics indicate recognition events in the early hours of a dinoflagellate/coral symbiosis. Mar Biol 149:713-719

Rowan R, Knowlton N, Baker A, Jara J (1997) Landscape ecology of algal symbionts creates variation in episodes of coral bleaching. Nature 388:265-269

Savage AM, Trapido-Rosenthal H, Douglas AE (2002) On the functional significance of molecular variation in Symbiodinium, the symbiotic algae of Cnidaria: photosynthetic response to irradiance. Mar Ecol Prog Ser 244:27-37

Tchernov D, Gorbunov MY, de Vargas C, Yadav SN, Milligan AJ, Haggblom M, Falkowski PG (2004) Membrane lipids of symbiotic algae are diagnostic of sensitivity to thermal bleaching in corals. Proc Natl Acad Sci USA 101: 13531-13535

Thornhill DJ, LaJeunesse TC, Kemp DW, Fitt WK, Schmidt GW (2006) Multi-year, seasonal genotypic surveys of coral-algal symbioses reveal prevalent stability or postbleaching reversion. Mar Biol 148:711-722

Weis VM, Reynolds WS, deBoer MD, Krupp DA (2001) Host-symbiont specificity during onset of symbiosis between the dinoflagellates Symbodinium spp. and planula larvae of the scleractinian coral Fungia scutaria. Coral Reefs 20:301-308

Submitted: August 3, 2007; Accepted: August 25, 2007

Proofs received from author(s): September 3, 2007 